\title{
Assessment of the quality (comfort) of the living environment in urban conditions
}

\author{
Nina Fomina ${ }^{1, *}$, Alexander Lugovskoy ${ }^{1,2}$ \\ ${ }^{1}$ Moscow Region State University, 10A, Radio str., 105005, Moscow, Russia \\ ${ }^{2}$ Moscow State University of Geodesy and Cartography, 4, Gorokhovsky Per., 105125, Moscow, \\ Russia
}

\begin{abstract}
A universal methodological approach to the geo-ecological assessment of the comfort of the living environment for population was developed, which can be applied in practice, including by non-specialists. The selection of factors and criteria is based on a review of the literature on assessing the quality (comfort) of the living environment. The main factors and criteria that have the greatest impact on the quality of the living environment for the population are ecological, urban planning, landscape, and social ones. Each group of factors is calculated quantitatively (based on a set of criteria and indicators), taking into account the obtained class coefficients based on the results of an expert survey. The territory of the municipality of Balakovo city in the Saratov region is studied. There are 5 levels of comfort of living of the population. The best quality of the urban environment for living was observed in old-developed areas, the worst - in new neighborhoods located on the periphery and adjacent to industrial zones.
\end{abstract}

\section{Introduction}

In a broad sense, the term "quality of the living environment" is interpreted as the satisfaction of the population with their life in terms of various needs and interests. This approach considers various economic categories, working and leisure conditions, housing conditions, social security and guarantees, law enforcement and respect for individual rights, natural and climatic conditions, indicators of environmental conservation, etc. The generalized indicator of the quality of the environment of the studied territory includes the level of material, ecological, cultural and spiritual welfare of a person.

The quality (comfort) of the living environment provides an assessment and comparison of the values of its indicators in the temporal or spatial aspect. Various approaches and methods have been developed to assess the quality and comfort of the living environment for population:

- General index of attractiveness of cities (GIAC). 41 indicators are studied, which are combined into blocks in areas that form 13 indices (population dynamics, environmental situation, housing affordability, engineering infrastructure, human resources, etc.), on the basis of which the GIAC was obtained [14].

\footnotetext{
${ }^{*}$ Corresponding author: fominanina12@mail.ru
} 
- The urban environment quality index is formed by the Ministry of Construction and Housing and Utilities of the Russian Federation. It is calculated based on 36 indicators (the share of the population living in emergency housing, the level of landscaping, the variety of residential development, the variety of services in the residential area and in public and business areas, etc.) [7].

- True progress indicator (GPI). It includes more than 20 aspects of economic life: time spent on household management, child care, volunteer work, costs of losses from crime, car accidents, environmental pollution, social costs, etc. [15].

- The scale of happiness of Veenhoven (HLE). It is calculated as the composition of life expectancy in years and the happiness index averaged in a sample survey. The happiness index is calculated as a self-assessment using a ten-step "happiness ladder" [20].

- Quality of life-oriented health indicator (HRQOL). The basis of this indicator is the concept of health, which is a fundamental basis for assessing the quality of life. The calculation is based on the results of research and social surveys.

- The indicator of economic well-being (IEWB). The index is based on four components: the level of personal consumption; savings per capita; inequality in the distribution of individual income; economic security [19] and other indicator systems.

The purpose of this work is to study the quality of life in urban conditions and develop a universal methodological approach to the geo-ecological assessment of the quality (comfort) of the population's living environment for non-specialists, according to which they will be able to assess the quality of life in the city (for the purpose of organizing urban space (architectural bureaus), real estate transactions (realtors), making amendments to the existing social and economic policy of the city (ordinary citizens and representatives of organizations)).

\section{Materials and methods of the research}

The methodology of construction and interpretation of factors and criteria should correspond to specific types of tasks of their application, in this case, the study of the quality of the living environment [1].

The analysis of works $[5,6,11,16]$ revealed the main groups of factors that directly affect the comfort of living. To identify the significance of the contribution of each factor and criterion, it was decided to introduce class coefficients of importance. They were obtained by conducting an individual expert survey. Its advantages are independence of judgment, decision-making in a calm situation, etc. [8, 9, 10, 17].

The correlation coefficient allowed us to determine the tightness of the relationship between the samples. We used the classical correlation coefficient [17] calculated by the formula:

$$
R=\frac{\sum_{i=1}^{n}\left(x_{i}-\bar{x}\right)\left(y_{i}-\bar{y}\right)}{n \sigma_{x} \sigma_{y}}, \ldots
$$

where $x_{i}$ and $y_{i}$ - are the results of the survey of two compared experts, expressed in quantitative form; $\bar{x}$ and $\bar{y}$ - are the average values of the sample; $\mathrm{n}$ - is the number of members of the series equal to the number of evaluated factors; $\sigma_{x}$ and $\sigma_{y}$ - are the average square deviations equal to:

$$
\begin{gathered}
\sigma_{x}=\sqrt{\frac{1}{n-1} \sum_{i=1}^{n}\left(x_{i}-\bar{x}\right)^{2}}, \ldots \\
\sigma_{y} \sqrt{\frac{1}{n-1} \sum_{i=1}^{n}\left(y_{i}-\bar{y}\right)^{2}}, \ldots
\end{gathered}
$$


The Harrington scale was used to evaluate the obtained average correlation coefficients (table 1).

The scales of the initial variables $x^{(j)}$, monotonically related to the quantitative assessment of the analyzed factors and criteria, were transferred to the converted indicators $\tilde{x}^{(j)}$, associated with the original variables $x^{(j)}$ by the transformation $[2,3]$ :

$$
\tilde{x}=\frac{x^{(j)}-x_{\min }^{(j)}}{x_{\max }^{(j)}-x_{\min }^{(j)}}, \ldots
$$

where $x_{\min }$ and $x_{\max }$ - are the smallest and largest possible values of the $\mathrm{j}$-th initial quality characteristic. Converted values of factors and criteria (j-th characteristic) $\tilde{x}^{(j)}$ can take values from $\tilde{x}^{(j)}=0$ (which corresponds to the best quality) to $\tilde{x}^{(j)}=1$ (which corresponds to the worst quality). Under condition, that the higher the $\mathrm{x}(\mathrm{j})$ score, the worse the quality.

Table 1. The verbal-numerical Harrington scale.

\begin{tabular}{|c|c|}
\hline Average correlation coefficient & The degree of consistency of expert judgments \\
\hline $0.0-0.20$ & Minor \\
\hline $0.21-0.37$ & Low \\
\hline $0.38-0.64$ & Average \\
\hline $0.65-0.80$ & High \\
\hline $0.81-1.00$ & Very high \\
\hline
\end{tabular}

The research was conducted using the following algorithm:

1. creating a database of factors and criteria under study;

2. calculation of criteria for indicators using scoring scales and expert evaluation of criteria and groups of factors;

3. grouping of micro districts that fall within the same ranges of quality of life;

4. zoning of the territory according to the main levels of quality of life of the population.

The object of research was chosen Balakovo city in Saratov region. Over the past few decades, its territory has been characterized by a significant anthropogenic load, which negatively affects the attractiveness of the city for life [18].

According to the urban environment quality index, the city is ranked 34 out of 93 in its group and 4 among the cities of the region (Saratov region) [7] and is at a level above average in terms of the quality of the environment for life. However, the current demographic situation indicates that Balakovo city is not attractive for living (figure 1). Therefore, it is necessary to determine a different approach to assessing the comfort of living.

For its evaluation it was decided to adopt the existing city division into micro districts: the island (Zhilgorod, Stariy gorod, town of Dzerzhinsky, SNT Zelenaya Roshcha, SNT Dary Prirody), off-channel (1-4 micro district, Juzhniy Sazanley, Vostochniy Sazanley), central (5-11 micro district, town Raduzhniy, 21 micro district, Solnechniy) (figure 2). 


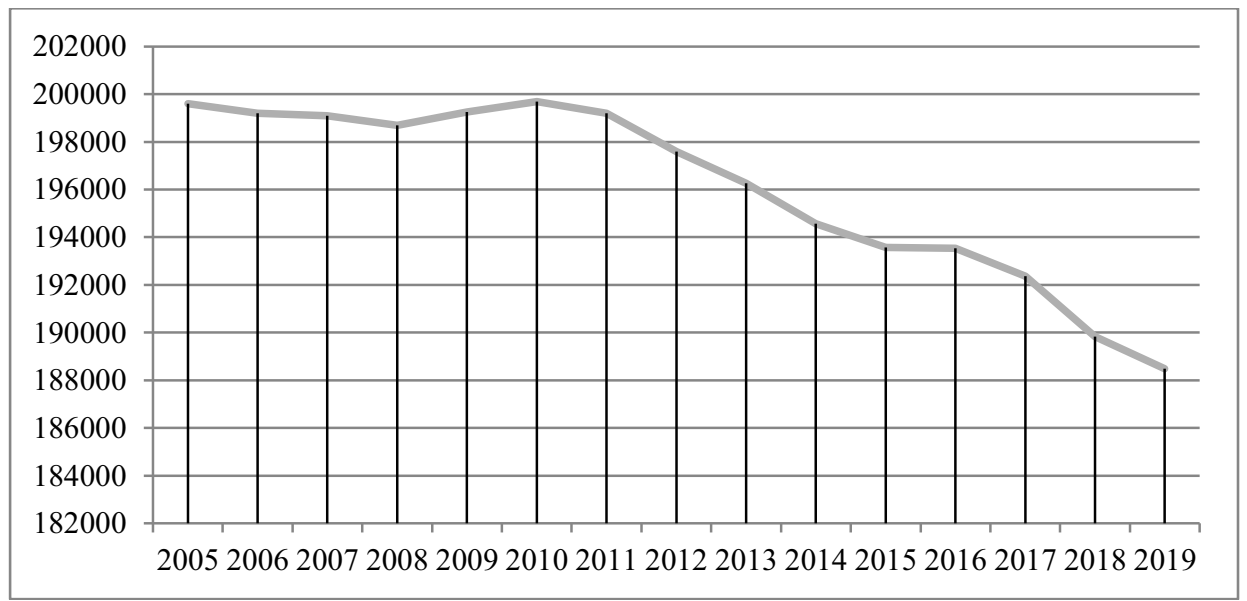

Fig. 1. Dynamics of the population of Balakovo city 2005-2019.

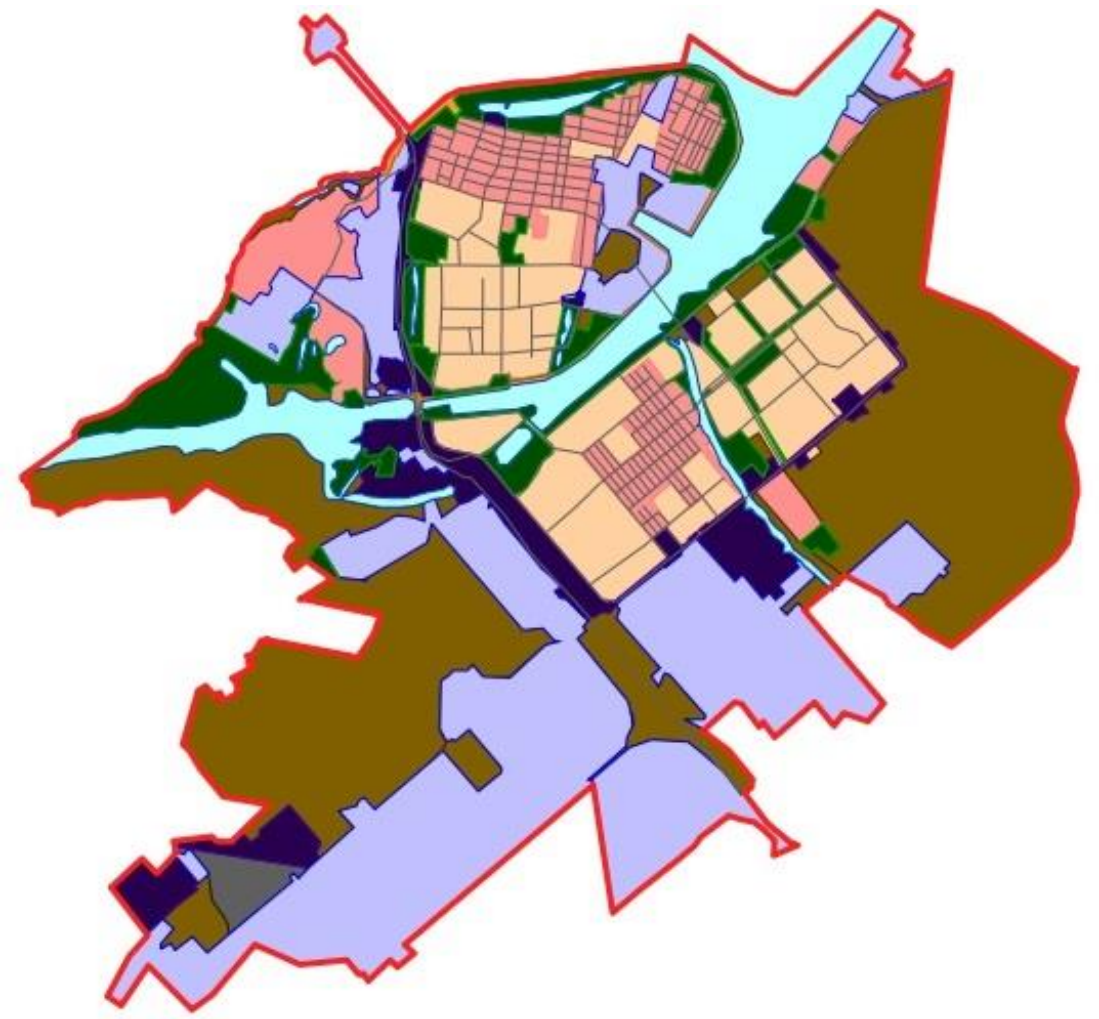

Convention

Borders

\section{Balakovo city} roads

Functional zones

low-rise residential development zone zone of residential multistory and public buildings hydroelectric construction zone zone of engineering and transport facilities industrial development zone green space zone public use and forest fund reservoirs, rivers, channels, etc. polygon for solid waste others 


\section{Results and discussion of the research}

As a result of processing expert judgments, a table was created (the number of rows in the table is equal to the number of indicators, and the number of columns is equal to the number of experts). The class coefficients were found by averaging all estimates $[9,10]$. The degree of consistency of experts was checked using correlation analysis. The expert survey made it possible to identify the degree of contribution of each factor and criterion to the overall level of geo-ecological comfort of the population living (figure 3 ).

The variety of ideas about the environment, including urban, determines the multiplicity of existing subject approaches to its assessment (sociological, sanitary, technological, urban planning, etc.), as well as to the assessment of its individual components and aspects (depending on the subject drawing of the environment). The quality of the environment for the population's life was determined by a combination of various favorable conditions: natural and environmental, social, and urban planning (table 2).

The selected indicators are intended to be as accessible as possible for calculation. For example, ecological factors are a set of criteria and indicators that reflect physical parameters. This, on the one hand, does not provide accurate data on the pollution of geospheres, but on the other hand, it is the most accessible indicator of the quality of the environment for human life. The natural desire to diversify existing planning and architectural solutions, the presence of a historically developed urban landscape predetermined the choice of urban planning and landscape (aesthetic) factors.

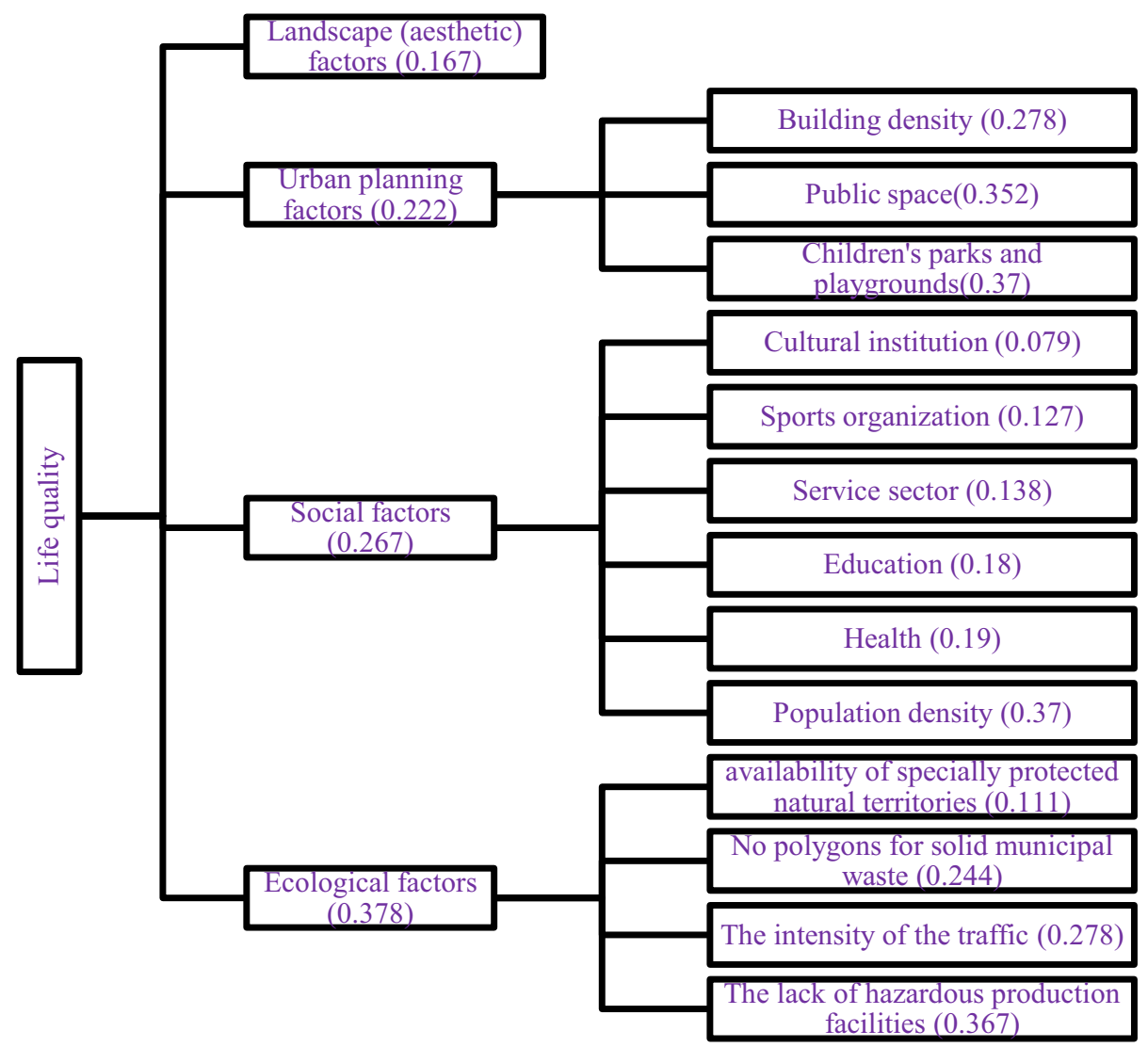

Fig. 3. Factors and criteria for comfortable living of the population with the degree of their contribution according to the results of an expert survey (with class coefficients). 
The availability of information for calculations played a fundamental role in the development of the criteria system. The lack of reliable data and the ability to perform laboratory research significantly highlights publicly available information, and here the main task is to be able to process this information and apply it in practice.

Table 2. The factors, criteria and indicators for the calculation.

\begin{tabular}{|c|c|c|}
\hline Factors & Criteria & Indicator \\
\hline \multirow[t]{4}{*}{ Ecological } & $\begin{array}{l}\text { Hazardous production } \\
\text { facility }\end{array}$ & $\begin{array}{l}\text { Average distance to the object, taking into account } \\
\text { the rank of the enterprise }(\mathrm{km})\end{array}$ \\
\hline & $\begin{array}{l}\text { The intensity of the } \\
\text { traffic }\end{array}$ & Traffic intensity (vehicles/h) \\
\hline & $\begin{array}{l}\text { Polygons for solid } \\
\text { municipal waste }\end{array}$ & Average distance to the object $(\mathrm{km})$ \\
\hline & $\begin{array}{l}\text { Specially protected } \\
\text { natural territories }\end{array}$ & $\begin{array}{l}\text { Average distance to the object, taking into account } \\
\text { the protected area rank }(\mathrm{km})\end{array}$ \\
\hline \multirow[t]{6}{*}{ Social } & Population density & $\mathrm{h} / \mathrm{km}^{2}$ \\
\hline & Health & $\begin{array}{l}\text { In accordance with the set of rules } \mathrm{SP} \\
42.13330 .2011[13]\end{array}$ \\
\hline & Education & $\begin{array}{l}\text { In accordance with the set of rules } \mathrm{SP} \\
42.13330 .2011\end{array}$ \\
\hline & Service sector & $\begin{array}{l}\text { Provision of residential services to the population } \\
\text { of the micro district (number) }\end{array}$ \\
\hline & Sport organizations & Availability (number) of sports facilities \\
\hline & Cultural institution & $\begin{array}{l}\text { The presence (number) of institutions of cultural } \\
\text { and leisure type }\end{array}$ \\
\hline \multirow[t]{3}{*}{ Urban planning } & Building density & $\begin{array}{l}\text { The ratio between the area of buildings and the } \\
\text { area of land (thousand } \mathrm{m}^{2} / \mathrm{ha} \text { ) }\end{array}$ \\
\hline & Public space & $\begin{array}{l}\text { The ratio of the area of public spaces to the total } \\
\text { area of the micro district }\end{array}$ \\
\hline & Children's parks & $\begin{array}{l}\text { Ratio of the area of children's parks to the } \\
\text { population of the micro district }\end{array}$ \\
\hline Landscape & $\begin{array}{l}\text { The aesthetics of the } \\
\text { landscape }\end{array}$ & $\begin{array}{l}\text { The presence of picturesque tracts, attractions, a } \\
\text { sense of comfort from contemplating the } \\
\text { landscape, etc., expressed in points [4] }\end{array}$ \\
\hline
\end{tabular}

The expression for calculating the total estimates of the integral indicator of the quality of life $(\mathrm{Q})$ of the population in the micro districts of Balakovo city, taking into account the intergroup coefficients, has the following form:

$$
Q=\sum_{i}^{n} k_{i} I_{i}, \ldots
$$

where, $k_{i}$ - is the weight of the factor, $i=1 \ldots n$ - is the number of factors, and $I_{i}$ - is the value of the factor.

The resulting total scores were ranked according to the principle: the higher the score, the higher the quality of the living environment. 5 ranks of quality of life of the population in the territory of Balakovo city are allocated (figure 4).

A high level of comfort is typical for micro districts that were leaders in environmental quality in several groups of factors, which allowed them to take the status of the most comfortable in comparison with the others (figure 5). Comfort of micro districts above the average level is disproportionate, one or two areas (engineering, ecological or social) are insufficiently developed. Micro districts with an average level are characterized by insufficient development, two or three factors are studied. For at least three groups of factors, micro districts ranked below average are within the low comfort range. For each group of indicators, low-level districts are in a low-comfort zone. 


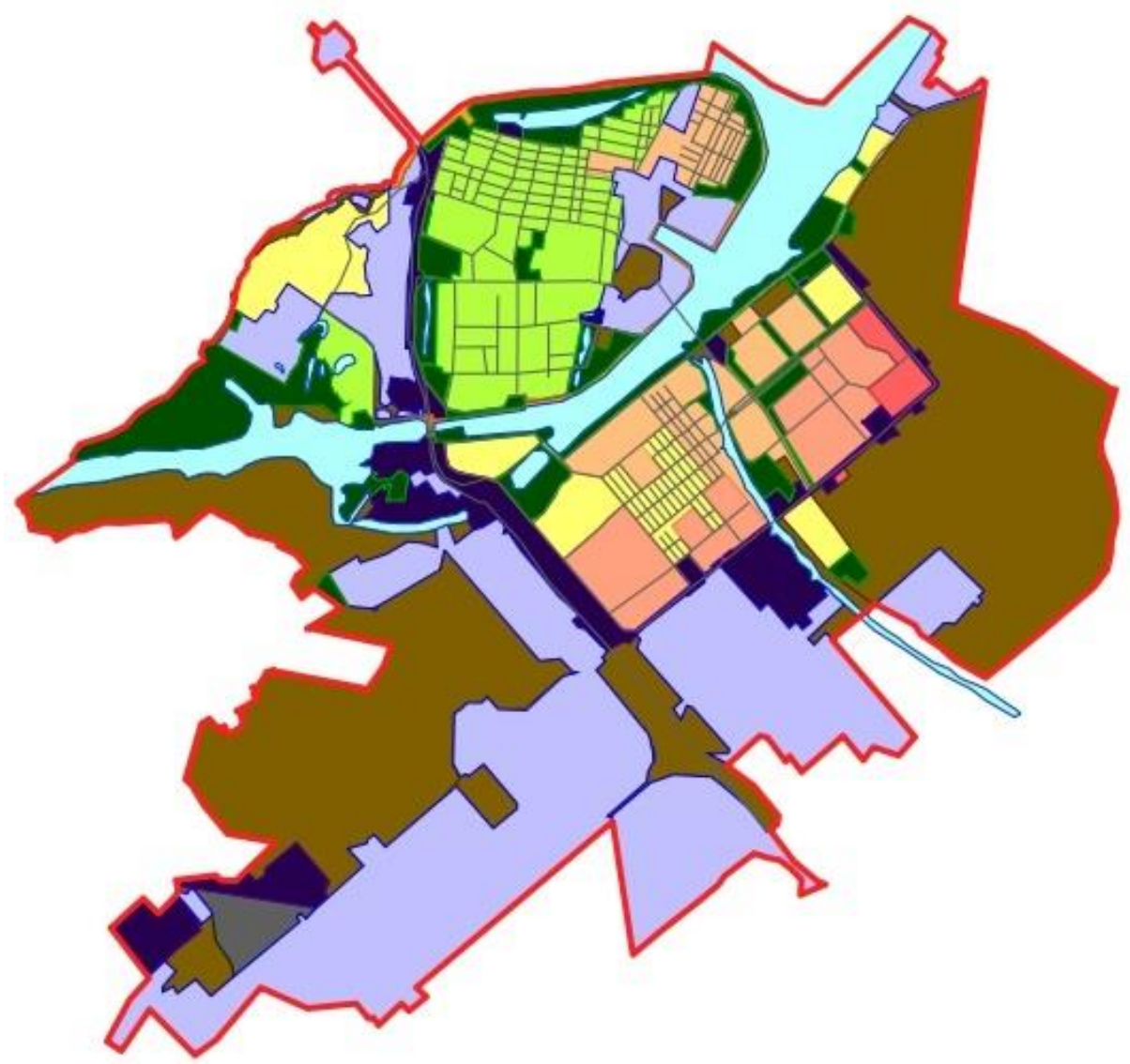

Convention

Borders

Balakovo city roads

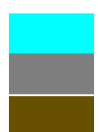

Functional zones

hydroelectric construction zone zone of engineering and transport facilities industrial development zone green space zone public use and forest fund reservoirs, rivers, channels, etc. polygon for solid waste others

Level of comfort of living low below the average average above the average high

Fig. 4. Zoning of the territory of Balakovo city by comfort of living. 
High
$\cdot$ Stariy gorod, Zhilgorod, Zelenaya Roshcha

Above the avrage
•Dary Prirody, 1-st, 2-nd, 7-th micro districts, Juzhniy Sazanley, Solnechniy micro district,
Raduzhniv

Average

•town of Dzerzhinsky, 3, 5, 5a, 6, 8a, Vostochniy Sazanley

Low

$\cdot 9 a, 11$ and 21

Fig. 5. Ranking of micro districts in Balakovo city by the quality of the living environment for the population.

The following trend is noted: the most comfortable for living are the old-developed parts of the city (island), which have such advantages as low-rise buildings, developed infrastructure, distance from hazardous production facilities. And, on the contrary, in the micro districts of the off-channel and central parts there is a low level of quality of the environment for life: point buildings with a high population density, high traffic intensity, proximity to dangerous production facilities, etc.

The current level of urban planning, the current ecological and demographic situation, and the geo-ecological assessment carried out on the basis of their deep analysis emphasize the urgent need to make decisions to optimize living conditions in Balakovo city. The proposed method can act as a controller in the design of new micro districts and the reorganization and renovation of existing ones, since it is based on both landscape and urban planning conditions, setting thresholds for the comfort of living under existing conditions.

\section{Conclusion}

In research on assessing the quality (comfort) of the living environment, it is proposed to use a comprehensive index of geo-ecological comfort, obtained on the basis of the results of the study of factors affecting it, and the analysis of an individual expert survey. This is an integrated index that characterizes the number and intensity of connections between various groups of factors that affect the quality of the living environment.

The proposed method has a set of advantages such as: the use of available information, prompt diagnostics of the condition of municipal micro districts and rapid identification of problem areas, the possibility of a comprehensive assessment, the possibility of intraterritorial comparison, objective and reasonable methods of convolution of indicators in the transition to integral factors. The included block of video-ecological orientation (architectural and landscape features of micro districts) allows us to identify, among other 
things, the psycho emotional component of living on the territory, which can be used in further research and applied works.

\section{References}

1. S.A. Ayvazyan, Analysis of the quality and lifestyle of the population, Central Economic and Mathematical Institute of the Russian Academy of Sciences (Moscow, Nauka, 2012)

2. S.A. Ayvazyan, Applied econometrics 2, 84 (2006)

3. S.A. Ayvazyan, Inter-country analysis of integral categories of quality of life of the population (econometric approach) (Moscow, CEMI RAS, 2001)

4. L.I. Atkina, M.V. Zhukova, Aesthetics of the landscape: study guide (Yekaterinburg, Ural State Forest Engineering Univercity, 2017)

5. T.A. Dolgacheva, Assessment of comfort of living of the population in the city (on the example of Saransk): autoabstract dissertation...Candidate of geographical sviences (Kaluga, 2006)

6. I.S. Glebova, Scientific notes of the Kazan University 153(4), 198 (2011)

7. Urban environment quality index, https://xn----dtbcccdtsypabxk.xn--p1ai/\#/

8. V.B. Korobov, Scientific dialogue 3(15), 94 (2013)

9. V.B. Korobov, Sociological research 11, 102 (2003)

10. V.B. Korobov, Expert methods in geography and geo-ecology: monograph (Arkhangelsk, Pomor University, 2008)

11. Y.N. Merinov, Ecological and social convenience of the urban environment of Rostovon-Don (Rostov-on-Don, Publishing house of Rostov State University, 2001)

12. L. Akhmetshina, A. Sergeev, A. Mottaeva, E3S Web of Conferences 91, 06008 (2019) https://doi.org/10.1051/e3sconf/20199106008

13. Set of rules SP 42.13330.2011 SNiP 2.07.01-89. Updated version of SNiP 2.07.01-89 (approved by the order of the Ministry of Regional Development of the Russian Federation from December 28, 2010 N 820)

14. Modern Production Technologies. Population life quality, https://extxe.com/15360/kachestvo-zhizni-naselenija/

15. N. Tulebayeva, D. Yergobek, G. Pestunova, A. Mottaeva, Z. Sapakova, E3S Web of Conferences 159, 01012 (2020) https://doi.org/10.1051/e3sconf/202015901012

16. V.O. Stulyshapku, Assessment of environmental and social comfort of population living at the local level: dissertation...Candidate of geography sciences (Kaluga, 2006)

17. A. Mottaeva, A. Ivashchenko, A. Ryattel, E3S Web of Conferences 164, 10038 (2020) https://doi.org/10.1051/e3sconf /202016410038

18. N. Fomina, A. Lugovskoy, Collection of Dobrodeevsky readings - 2018 II international scientific and practical conference, 152 (2018)

19. Osberg L., Sharpe Social Indicators Research 58, 349 (2002)

20. R. Veenhoven, Social Indicators Research 39, 1 (1996)

21. E. Ganebnykh, T. Burtseva, N. Mironova, and O. Feoktistova, E3S Web of Conferences 110, 01077 (2019) DOI: 10.1051/e3sconf /201911001077

22. E. Ganebnykh, T. Burtseva, A. Petukhova, and A. Mottaeva, E3S Web of Conferences 91, 08035 (2019) DOI: 10.1051/e3sconf/201991080 